\title{
Enhancing Mar and Abrasion Resistance of Acrylic Hard Coatings with Soft Base Layer
}

\author{
Patcharida Chouwatat1, Masaya Kotaki2,3*, Atsushi Yokohama1 \\ ${ }^{1}$ Department of Advanced Fibro-Science, Kyoto Institute of Technology, Kyoto, Japan \\ ${ }^{2}$ Kaneka US Material Research Center, Kaneka Americas Holding, Inc., Pasadena, Texas, USA \\ ${ }^{3}$ Center for Fiber and Textile Science, Kyoto Institute of Technology, Kyoto, Japan \\ Email: *masaya.kotaki@kaneka.com
}

Received 17 November 2015; accepted 15 January 2016; published 18 January 2016

Copyright (C) 2016 by authors and Scientific Research Publishing Inc.

This work is licensed under the Creative Commons Attribution International License (CC BY). http://creativecommons.org/licenses/by/4.0/

(c) (i) Open Access

\begin{abstract}
Mar and abrasion resistance were investigated by a progressive load scratch test and steel wool abrasion test, respectively. Two acrylic coating systems including trimethylolpropane triacrylate (TMPTA) and pentaerythritol triacrylate (PETA) were prepared. A soft base layer was introduced as an intermediate layer between two different types of top layer and poly (methyl methacrylate) (PMMA) substrate to demonstrate the effect of soft base layer on mar and abrasion resistance. Abrasion damage on the coating surface was found to be less severe, when the soft base layer was incorporated into the coating systems. The reduction in scratch coefficient of friction (SCOF) and surface roughness was also observed. The results suggested that mar and abrasion resistance was greatly influenced by the presence of soft base layer, although different top layers were used. Moreover, it was found that abrasion resistance was further improved as the thicker soft base layer was applied.
\end{abstract}

\section{Keywords}

Acrylic Coating, Soft Base Layer, Mar Resistance, Abrasion Resistance

\section{Introduction}

Transparent polymeric materials have been utilized for various applications such as automobile windows, optical lenses and displays for electronic devices [1]-[5]. However, it is well-known that polymer materials having excellent optical transparency show poor abrasion resistance [6]-[8]. Thus, polymer hard coatings such as acrylic coatings have been developed to decorate and protect surface of polymer substrate without compromising

\footnotetext{
"Corresponding author.
}

How to cite this paper: Chouwatat, P., Kotaki, M. and Yokohama, A. (2016) Enhancing Mar and Abrasion Resistance of Acrylic Hard Coatings with Soft Base Layer. Open Journal of Organic Polymer Materials, 6, 53-62.

http://dx.doi.org/10.4236/ojopm.2016.61006 
transparency [9]-[11]. In addition, to optimize coating performance, a number of factors influencing abrasion resistance have been investigated, for example, coating compositions, coating and substrate characteristics, coating thickness, adhesion [4] [12] [13], etc. It appears that those factors strongly influence abrasion resistance.

Therefore, a multilayer coating has been adopted to further improve the coating performance including chemical, mechanical and tribological properties [13] [14]. Each layer can provide a specific property, which has significant impact on tailoring the final coating performance. Moreover, it is found that combing coating layers with different mechanical properties can change the stress concentration in the surface area [13]. Sidorenko et al. demonstrated that a polymer trilayer film consisting of compliant rubber interlayer can be used as an abrasion resistant nanoscale coating with low friction coefficient for silicon surface [15]. This coating is prepared by a multiple grafting technique applied to self-assembled monolayers (SAM) and functionalized tri-block copolymer, followed by the photopolymerization of a topmost polymer layer. The compliant rubber interlayer can mediate localized stresses transferred through the top layer. Similarly, Vainshtein et al. emphasized an influence of soft base layer on scratch and abrasion resistance for oxide coating [16]. Polydimethylsiloxane (PDMS) is applied as soft intermediate layer between polycarbonate (PC) and titania. The presence of PDMS soft layer resulted in enhanced abrasion resistance and reduction in friction coefficient due to cushioning effect, which reduces the local stress. These studies indicate that soft base layer greatly influences abrasion resistance in nanoscale. However, the effect of soft base layer on macro-abrasion resistance and mar behavior for polymeric coating on polymer substrate has not been clarified yet.

Hence, herein, acrylic coatings, i.e. trimethylolpropane triacrylate (TMPTA) and pentaerythritol triacrylate (PETA), with and without soft base layer are applied on poly (methyl methacrylate) (PMMA) substrate. The influence of soft base layer on mar and abrasion behavior of acrylic coatings is investigated by using a progressive load scratch test (ISO 19252) and steel wool abrasion test, respectively. Moreover, the effect of soft base layer thickness on abrasion resistance is further demonstrated.

\section{Experimental}

\subsection{Coating Preparation}

Single- and bilayer coatings were prepared using UV curing technique. The formulations of each coating are listed in Table 1. A solution of top layer, i.e. trimethylolpropane triacrylate (TMPTA) and pentaerythritol triacrylate (PETA) was mixed with $5 \mathrm{wt} \%$ of photoinitiator, and then coated on $2 \mathrm{~mm}$-thick poly (methyl methacrylate) (PMMA) substrates using Mayer rod coating. The wet film was cured under ultraviolet light to obtain TMPTA and PETA single-layer coatings (TS and PS), respectively. The thickness of top layer was set at $30 \mu \mathrm{m}$.

For bilayer coatings, a soft base layer was introduced to the coating systems. A solution of soft base layer with $5 \mathrm{wt} \%$ of photoinitiator was applied on PMMA substrate, and exposed under ultraviolet light. The thickness of soft base layer was 5 and $15 \mu \mathrm{m}$. The solution of the top layer with $5 \%$ of photoinitiation was then coated on the soft base layer, and cured under the UV light to obtain the bilayer coatings with different soft base layer thickness: TB5, TB15, PB5, PB15.

Table 1. Formulations and critical normal load of scratch visibility for acrylic coatings.

\begin{tabular}{cccc}
\hline \multirow{2}{*}{ Sample ID } & \multicolumn{2}{c}{ Coating formulations } & \\
\cline { 2 - 3 } & Top layer materials & Soft base layer thickness $(\mu \mathrm{m})$ & Critical normal load for scratch visibility $(\mathrm{N})$ \\
TS & TMPTA & - & 5.8 \\
TB5 & 5 & Over $20 \mathrm{~N}$ \\
TB15 & 15 & Over $20 \mathrm{~N}$ \\
PS & & - & Over $20 \mathrm{~N}$ \\
PB5 & PETA & 5 & Over $20 \mathrm{~N}$ \\
PB15 & & 15 & Over $20 \mathrm{~N}$ \\
\hline
\end{tabular}




\subsection{Characterization}

Surface hardness of each layer was measured by direct imaging indenter (DII, SANKO Co., LTD) combining with a video camera and a transparent Berkovich tip to directly measure contact area. The soft base layer, TMPTA and PETA, was coated on glass substrates. Coating layer thickness was set at $25 \mu \mathrm{m}$. The test was conducted at room temperature under a load control mode set in the range from 0 to $30 \mathrm{mN}(5 \mathrm{sec})$ and from 30 to $0 \mathrm{mN}$ ( $5 \mathrm{sec}$ ). The hardness was calculated by the ratio of load to indented area.

Tensile properties of each layer were measured using a Universal Tensile Testing Machine (Instron model 4206). Free-standing films were prepared by UV curing technique. The dimension of specimens was $50 \mathrm{~mm}$ by $15 \mathrm{~mm}$. The thickness of specimen was $0.2 \mathrm{~mm}$. The test was conducted at room temperature with crosshead speed of $0.085 \mathrm{~mm} / \mathrm{s}$ and a gauge length of $15 \mathrm{~mm}$.

The progressive load scratch test according to ISO 19252 was conducted using a scratch instrument model KK-02 (KATO Tech Co.) at room temperature. Normal load was linearly increased from 1 to $20 \mathrm{~N}$. Scratch velocity and scratch length were set at $100 \mathrm{~mm} / \mathrm{sec}$ and $70 \mathrm{~mm}$, respectively. A $10 \mathrm{~mm}$ diameter of stainless steel ball tip was used to study on soft base layer effect on mar resistance. Five tests were performed, and the values obtained were averaged for each sample.

In addition, steel wool abrasion test was carried out at room temperature using a scratch instrument model KK-01 (KATO Tech Co.). The coating surface was rubbed for 100 cycles with \#0000 steel wool under constant load of $5 \mathrm{~N}$ and scratch velocity of $100 \mathrm{~mm} / \mathrm{sec}$. Scratch length was set at $50 \mathrm{~mm}$.

To evaluate abrasion resistance after scratch and abrasion test, haze was measured with NDH5000 haze meter (Nippon Denshoku Industries Co. Ltd.).

VK-X100 laser microscope (Keyence Corporation) was used to observe damage on the coating surface and surface roughness. The multi-file analysis software provided with the microscope was used to measure the surface roughness inside the abrasion path. The tilt correction available in the software was processed before measuring the surface roughness.

The more detailed damage was analyzed using field emission scanning electron microscopy (FE-SEM, Hitachi S4200) at an accelerating voltage at $8 \mathrm{kV}$. The coating samples were cut around the interesting point of damage, dried in vacuum overnight and coated with gold.

\section{Results and Discussion}

\subsection{Mar Behavior}

Acrylic coatings with and without soft base layer were prepared to clarify the effect of soft base layer on mar and abrasion resistance. Hardness and tensile properties of each coating layer were evaluated. The results are listed in Table 2. Hardness of soft base layer was about 50\% lower than that of TMPTA and PETA whereas in top layer TMPTA had 9\% higher hardness than PETA. In addition, the soft base layer showed lowest tensile modulus and largest elongation at break, while tensile strength at break of soft base layer was slightly higher than that of TMPTA but lower than that of PETA.

To study the effect of soft base layer on mar resistance, the progressive load scratch test according to ISO 19,252 was performed with $10 \mathrm{~mm}$ in diameter stainless steel ball tip. Scratched surfaces of each coating were carefully observed using laser microscope and SEM. The detailed damage at different Normal load for singleand bilayer coatings is showed in Figure 1 and Figure 2, respectively. Single layer coatings, i.e. TS and PS, started to have damages at very low Normal load and the damages became more severe with increasing Normal load (Figure 1). Obviously, in bilayer coatings (TB15 and PB15), mar damages were Not seen at low Normal

Table 2. Surface hardness and tensile properties of each coating layer.

\begin{tabular}{ccccc}
\hline \multirow{2}{*}{ Sample ID } & Surface hardness (MPa) & \multicolumn{3}{c}{ Tensile properties } \\
\cline { 3 - 5 } & & Tensile modulus (GPa) & Tensile strength at break (MPa) & Elongation at break (\%) \\
\hline TMPTA & 267 & 2.3 & 51.1 & 3.1 \\
PETA & 242 & 2.9 & 64.4 & 3.3 \\
Soft base layer & 132 & 1.5 & 53.9 & 6.0 \\
\hline
\end{tabular}




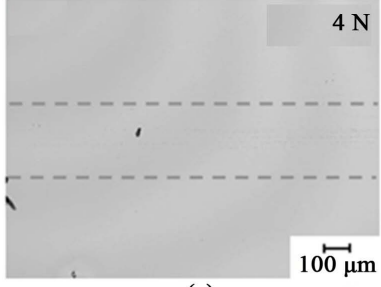

(a)

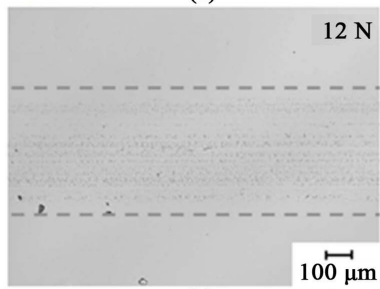

(b)

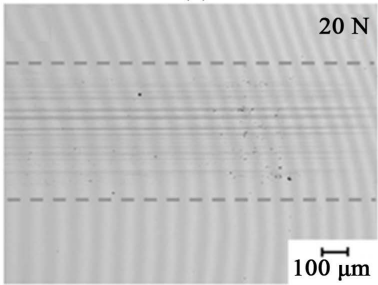

(c)

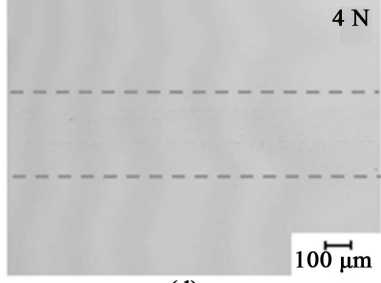

(d)

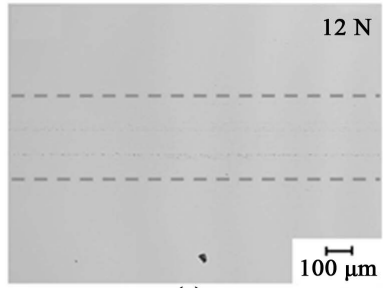

(e)

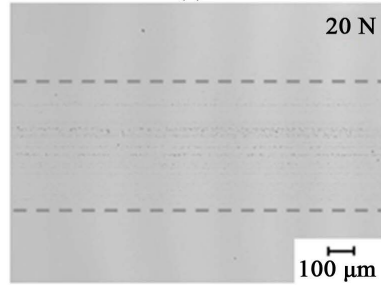

(f)

Figure 1. Mar damage on single-layer coating surfaces: (a)-(c) TMPTA and (d)-(f) PETA coating system.

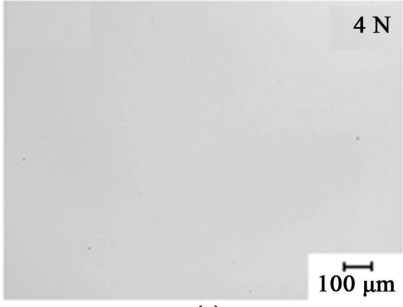

(a)

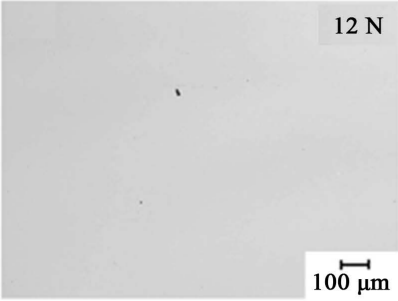

(b)

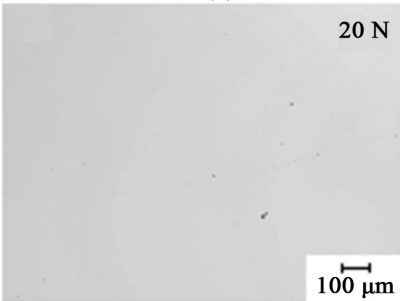

(c)

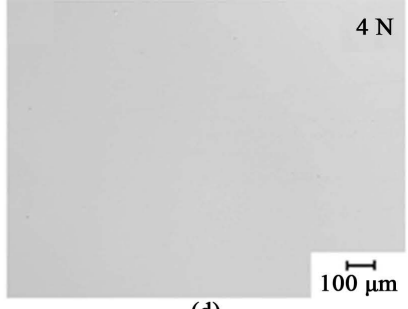

(d)

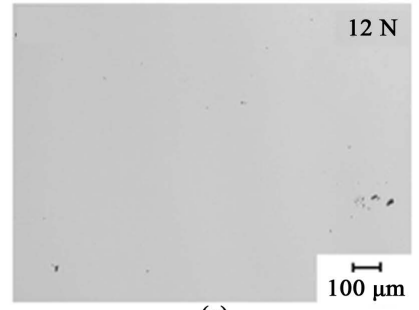

(e)

$20 \mathrm{~N}$

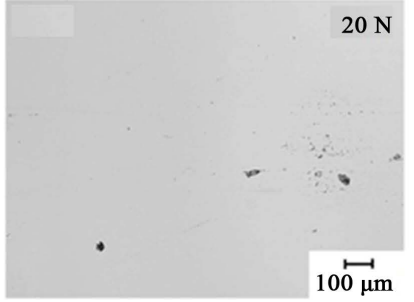

(f)

Figure 2. Mar damage on bi-layer coating surfaces: (a)-(c) TMPTA and (d)-(f) PETA coating system. 
load but became visible when normal load further increased up to $20 \mathrm{~N}$ (Figure 2). In addition, the effect of introduction of soft base layer on mar resistance is readily found in Figure 3. All bilayer coatings showed less severe mar damages than TS and PS. Moreover, the thicker soft base layer was introduced, the milder mar damages were observed. These indicate that the introduction of soft base layer significantly affects mar behavior, although the top layer is different.

The above results are greatly correlated to the scratch coefficient of friction (SCOF) curves in Figure 4. The SCOF curves were calculated by the ratio of the tangential force to the normal force [17]. It clearly sees that in both coating systems, the bilayer coatings had lower SCOF than the single layer coatings. This might be due to shallower penetration of scratch tip and less severe damage on the coating surface. For TMPTA system, the thicker soft layer resulted in reduction of SCOF. However, it was found that PB15 had higher SCOF than PB5 but showed milder damage (Figure 3 ). This might be due to wear debris that transfers from the coating surface to scratch tip and make the tip move more smoothly.

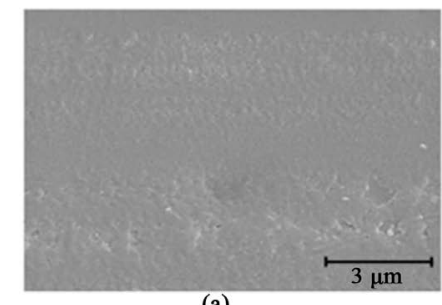

(a)

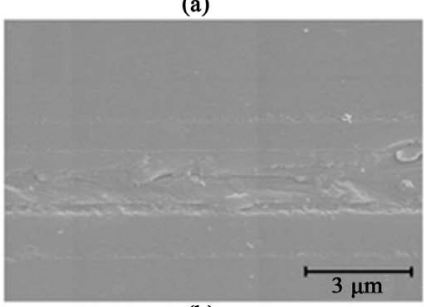

(b)

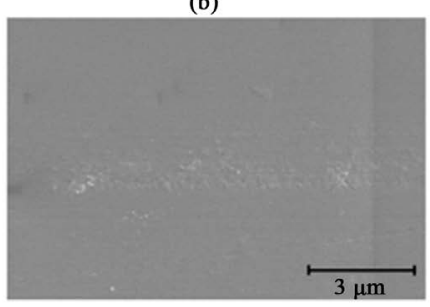

(c)

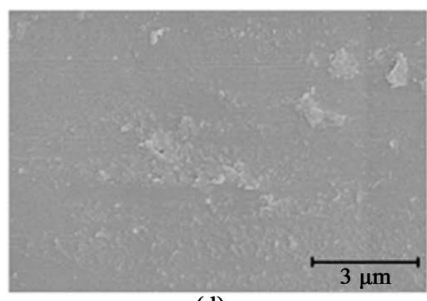

(d)

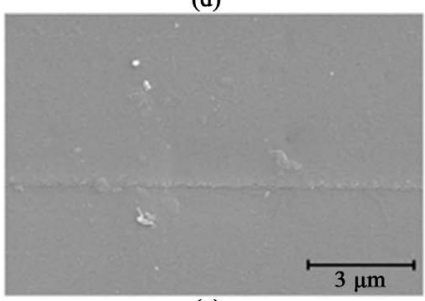

(e)

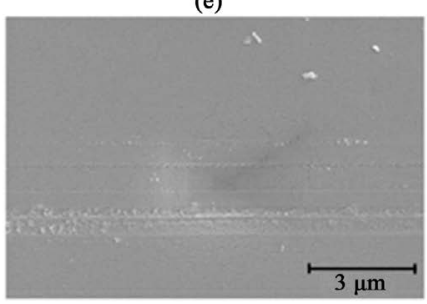

(f)

Figure 3. High-magnification SEM micrographs showing mar damage on coating surfaces at 20 N: (a) TS; (b) TB5; (c) TB15; (d) PS; (e) PB5 and (f) PB15.

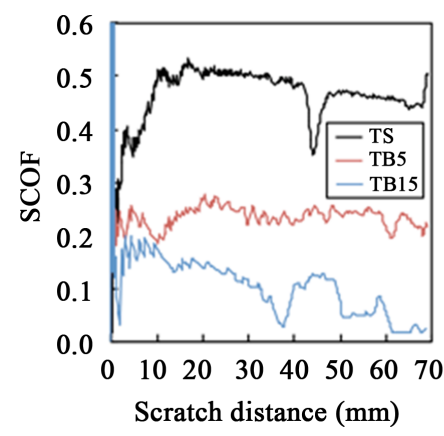

(a)

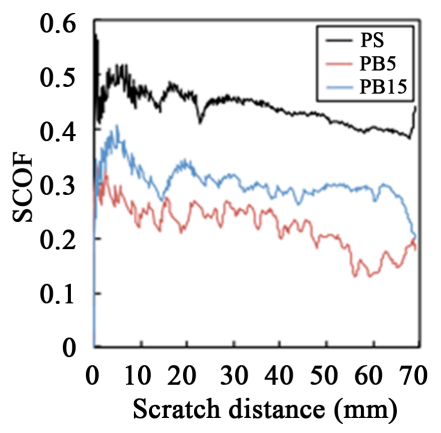

(b)

Figure 4. Comparison of SCOF curves from progressive load scratch test: (a) TMPTA and (b) PETA coating system. 
Since the surface damage may induce a change of the surface roughness that results in mar visibility and loss of gloss and/or transparency [13] [18], an onset of mar visibility was determined by naked eyes and then converted to a critical normal load for onset of mar visibility as presented in Table 1. A great improvement in mar visibility resistance was found as indicated by an increase in critical Normal load for onset of mar visibility when the soft layer was introduced into TMPTA coating system, while all coatings in PETA system exhibited excellent resistance to mar visibility.

However, the observation of mar visibility by naked eyes depends on many factors such as observation environmental condition and inspectors' sensitivity, making the evaluation more complicated and inconsistent [19]. Thus, to confirm the above result, haze measurement was performed. Figure 5 illustrates the relationship between haze values of each coating and normal load. It was found that the trends of haze values related well to the mar visibility result. For TMPTA system, the haze values in TS increased dramatically as normal load increased whereas TB5, TB15 and PETA system showed similar slopes of haze values and a gradual increase in haze values, relating to better mar visibility and mar resistance.

To clarify mechanism of mar behavior, surface roughness $\left(S_{a}\right)$ on the scratch groove at $20 \mathrm{~N}$ of normal load was measured. Figure 6 compares the surface roughness of each coating. Similar trend was observed in both coating systems. The introduction of soft base layer caused a decrease in surface roughness. Moreover, the surface roughness decreased with increasing the soft base layer thickness. It was also found that the surface roughness of TMPTA coating system was much higher than those of PETA coating system. This might be explained by the tensile properties. As the tensile properties play an important role in delaying or preventing an increase of scratch-induced surface roughness, the higher tensile strength leads to lower surface roughness on the scratch groove [13] [19] [20]. Correspondingly, PETA layer has higher modulus and tensile strength than TMPTA. Thus, PETA coating system shows lower surface roughness, correlating strongly with better resistance to mar visibility and mar.

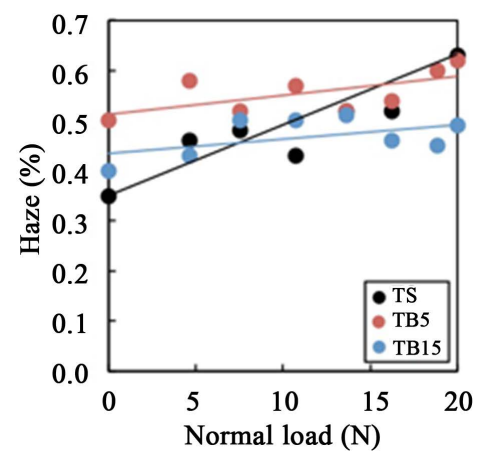

(a)

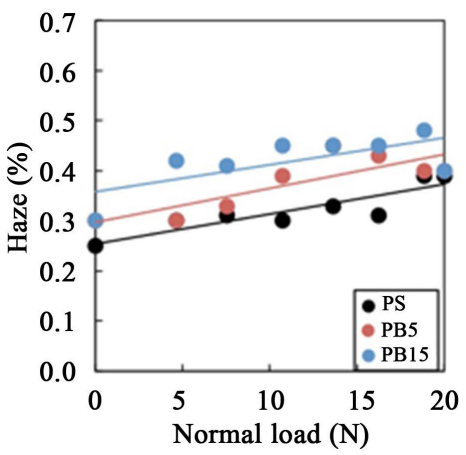

(b)

Figure 5. Haze values measured after progressive load scratch test: (a) TMPTA and (b) PETA coating system.

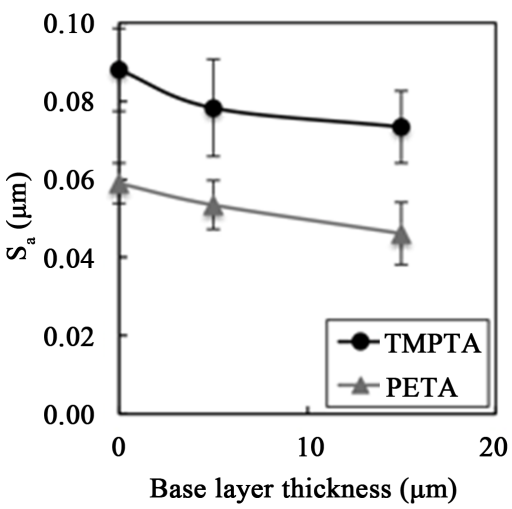

Figure 6. Surface roughness measured after progressive load scratch test. 


\subsection{Abrasion Behavior}

A steel wool abrasion test has been widely used in industries to evaluate the coating performance. In this work, a steel wool abrasion test was also utilized to verify the soft base layer effect. The relationship between the SCOF obtained from steel wool abrasion test and Number of test cycles is shown in Figure 7. The SCOF curves shot up at the beginning of the test and steady increased with further increasing test cycles. In TMPTA system, at the early abrasion test TS showed lowest SCOF whereas TB5 had highest SCOF (Figure 7(a)). The SCOF curves started to converge after 20 cycles. Conversely, PETA coating system exhibited the similar trend of SCOF at the early abrasion test but SCOF of PS diverged and was lower than PB5 and PB15 after 20 cycles (Figure 7(b)). This might be due to the fact that when the Number of test cycles increased, the large amount of debris transferred from the coating surface to steel wool, making the SCOF relatively low.

Figure 8 presents the haze values after steel wool abrasion test. It was found that the haze values of TS increase dramatically during the test while the haze values of TB5 and TB15 steadily increased after 30 cycles (Figure 8(a)). Moreover, considering the haze values after 100 cycles, it was found that the introduction of soft base layer into TMPTA system resulted in a significant decrease in haze values, relating to an improvement of abrasion resistance. The thicker soft layer led to better performance. However, the haze values in PETA coating system exhibited similar trend: they linearly increased as the number of cycles increased (Figure 8(b)).

The effect of introduction of soft base layer on abrasion behavior is readily observed in Figure 9 and Figure 10. Bilayer coatings showed less severe damage than single layer coatings. Moreover, the introduction of 15 $\mu \mathrm{m}$-thick soft base layer into both coating systems led to only minor abrasion damage (Figure 10(c) and Figure 10(f)). It is clearly evident that the presence of soft base layer in both coating systems causes marked decline in the surface roughness after 100 cycles (Figure 11), relating to enhanced abrasion resistance.

This present study emphasizes that abrasion resistance is strongly influenced by the soft base layer despite using different top layers and test methods. The thicker soft base layer results in better abrasion resistance. Furthermore, the SCOF decreases when the soft base layer is introduced. This might suggest that the introduction of

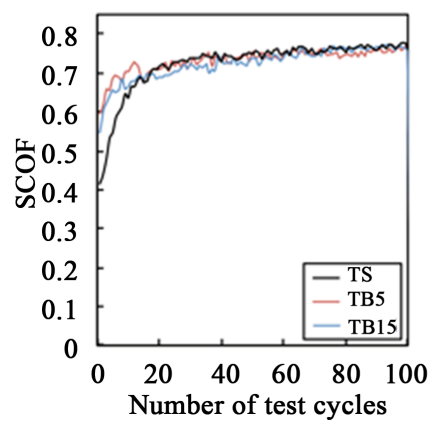

(a)

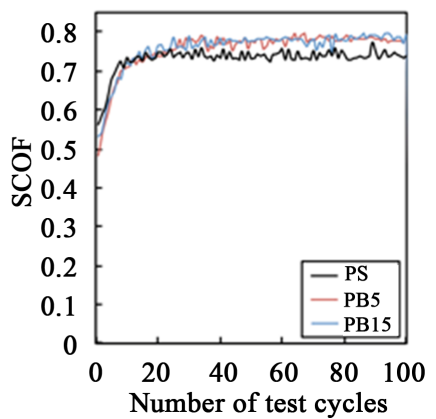

(b)

Figure 7. Comparison of SCOF curves from steel wool abrasion test: (a) TMPTA and (b) PETA coating system.

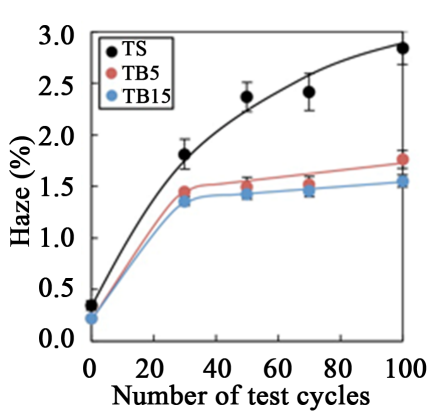

(a)

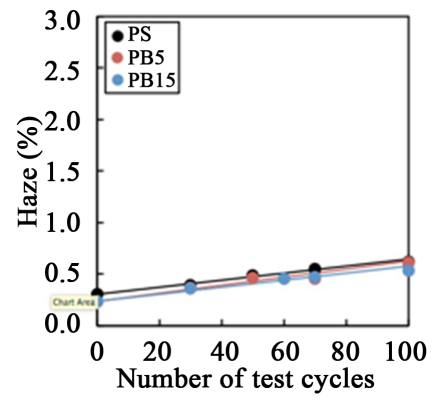

(b)

Figure 8. Haze values as a function of number of abrasion cycles: (a) TMPTA and (b) PETA coating system. 


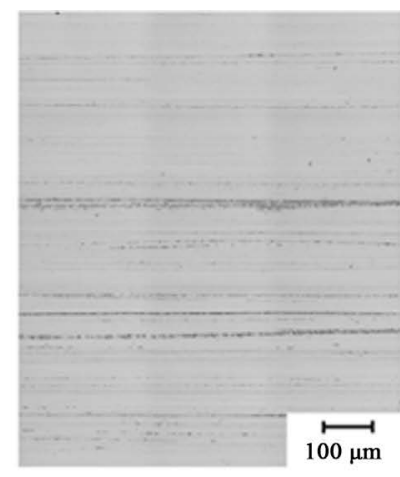

(a)

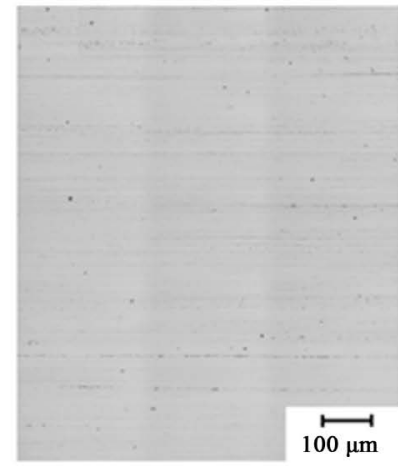

(b)

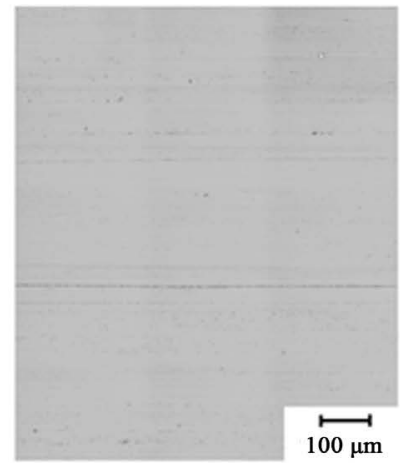

(c)

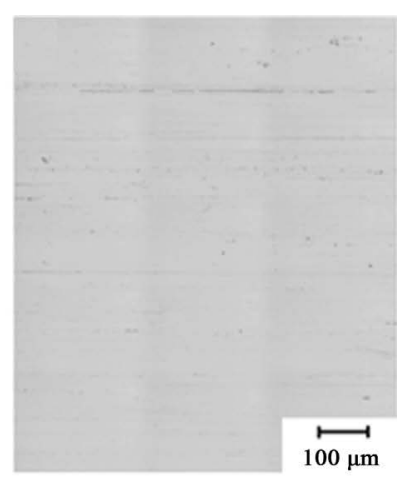

(d)

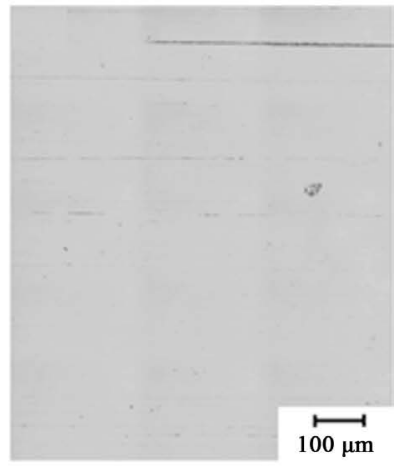

(e)

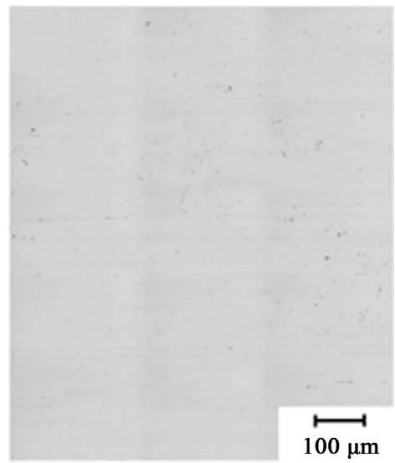

(f)

Figure 9. Abrasion damage observed after steel wool abrasion test: (a) TS; (b) TB5; (c) TB15; (d) PS; (e) PB5 and (f) PB15.

soft base layer can minimize the localized stress at the top surface due to the stress distribution. The thicker soft base layer results in less localized stress concentrated at the top surface.

\section{Conclusion}

The soft base layer effect on mar and abrasion resistance of acrylic coatings was investigated using progressive load scratch test and steel wool abrasion test. Both test method indicated that mar and abrasion resistance was greatly influenced by the presence of soft base layer. The SCOF and surface roughness significantly reduced when the coatings consisted of soft base layer. The introduction of soft base layer resulted in a marked improvement in mar and abrasion resistance, despite the fact that top layers were different. Furthermore, it was found that the thickness of soft base layer also affected mar and abrasion resistance. The thicker the soft base layer is, the better the abrasion resistance can be observed. 


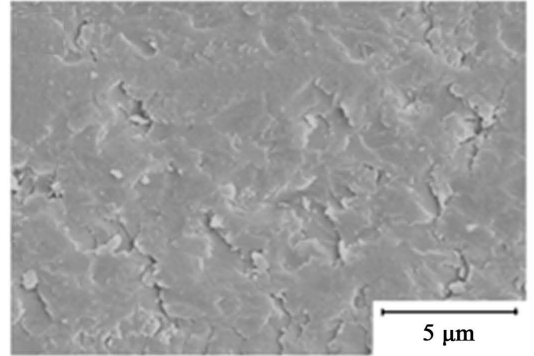

(a)

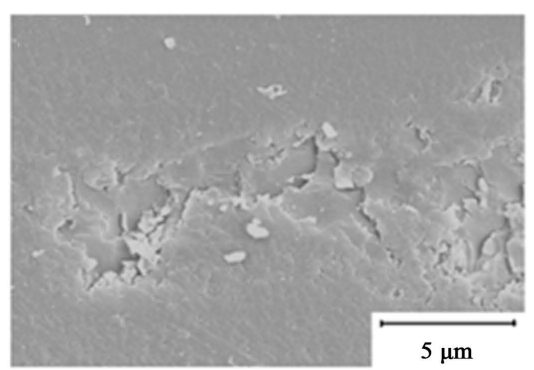

(b)

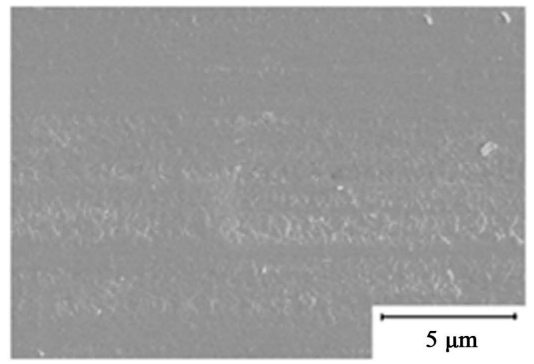

(c)

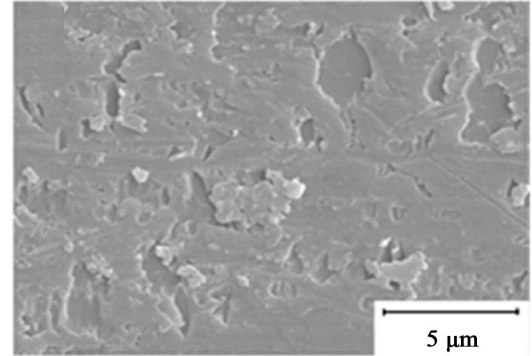

(d)

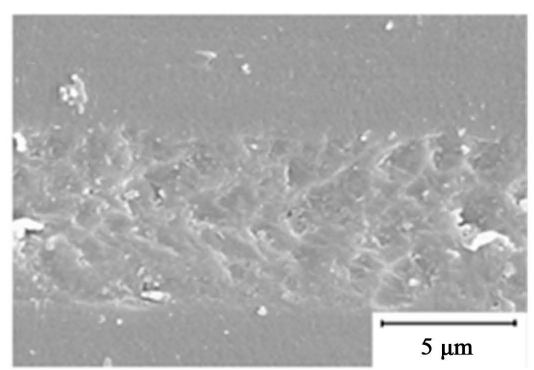

(e)

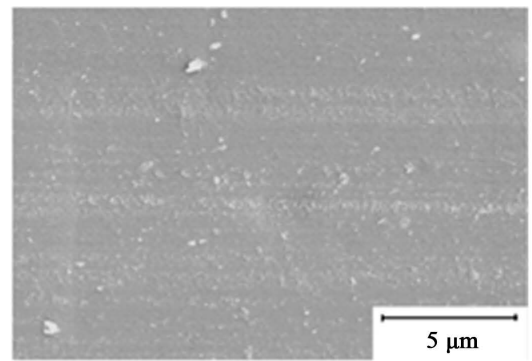

(f)

Figure 10. SEM micrographs showing abrasion damage from steel wool abrasion test: (a) TS; (b) TB5; (c) TB15; (d) PS; (e) PB5 and (f) PB15.

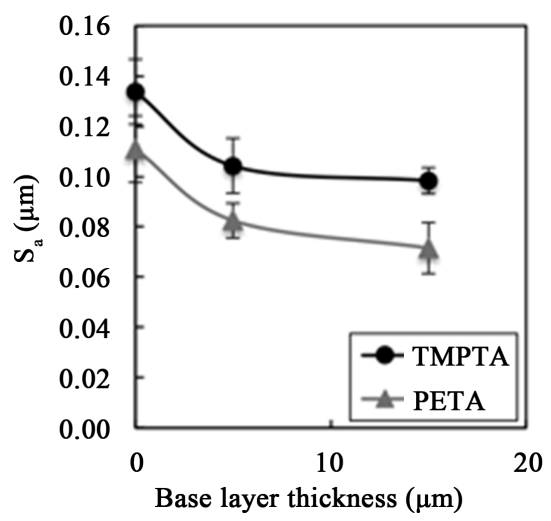

Figure 11. Surface roughness measured after steel wool abrasion test.

\section{Acknowledgements}

The authors would like to acknowledge Japan Scratch Consortium Society for insightful discussion regarding this research. We thank SANKO Co., Ltd. for conducting indentation test. We also thank Nippon Denshoku Industries Co. Ltd. for their support of haze meter in this study. 


\section{References}

[1] Schottner, G., Rose, K. and Posset, U. (2003) Scratch and Abrasion Resistant Coatings on Plastic Lenses—State of the Art, Current Developments and Perspectives. Journal of Sol-Gel Science and Technology, 27, 71-79. http://dx.doi.org/10.1023/A:1022684011222

[2] Schulz, U., Volker, W., Thomas, K. and Paul, A. (2001) The Influence of Weathering on Scratches and on Scratch and Mar Resistance of Automotive Coatings. Progress in Organic Coatings, 42, 38-48. http://dx.doi.org/10.1016/S0300-9440(01)00148-5

[3] Hozumi, A., Kato, Y. and Takai, O. (1996) Two-Layer Hard Coatings on Transparent Resin Substrates for Improvement of Abrasion Resistance. Surface and Coatings Technology, 82, 16-22. http://dx.doi.org/10.1016/0257-8972(95)02643-6

[4] Mackenzie, J.D. and Bescher, E. (2003) Some Factors Governing the Coating of Organic Polymers by Sol-Gel Derived Hybrid Materials. Journal of Sol-Gel Science and Technology, 27, 7-14. http://dx.doi.org/10.1023/A:1022659323517

[5] Rao, K.N. (2003) Studies on Thin Film Materials on Acrylics for Optical Applications. Bulletin of Materials Science, 26, 239-245. http://dx.doi.org/10.1007/BF02707798

[6] Wouters, M.E.L., Wolfs, D.P., van der Linde, M.C., Hovens, J.H.P. and Tinnemans, A.H.A. (2004) Transparent UV Curable Antistatic Hybrid Coatings on Polycarbonate Prepared by the Sol-Gel Method. Progress in Organic Coatings, 51, 312-319. http://dx.doi.org/10.1016/j.porgcoat.2004.07.020

[7] Kim, S.W. (2010) Characterization of UV Curable Hybrid Hard Coating Materials Prepared by Sol-Gel Method. Korean Journal of Chemical Engineering, 28, 298-303. http://dx.doi.org/10.1007/s11814-010-0338-9

[8] Gilberts, J., Tinnemans, A.H.A., Hogerheide, M.P. and Koster, T.P.M. (1998) UV Curable Hard Transparent Hybrid Coating Materials on Polycarbonate Prepared by the Sol-Gel Method. Journal of Sol-Gel Science and Technology, 11, 153-159. http://dx.doi.org/10.1023/A:1008693413965

[9] Schroeter, S.H. and Daniel, R.O. (1980) Abrasion Resistant Silicone Coated Polycarbonate Article. US Patent No. 4210699.

[10] Ogawa, M. and Hara, Y. (1988) Silicone-Based Coating Composition for Surface-Releasing Film. US Patent No. 4764576.

[11] Azuma, I., Kosaka, N., Iwamura, G., Marutani, Y. and Uemura, H. (1997) Acrylic Oligomer for High Solid Automotive Top Coating System Having Excellent Acid Resistance. Progress in Organic Coatings, 32, 1-7. http://dx.doi.org/10.1016/S0300-9440(97)00073-8

[12] Wu, L., Guo, X. and Zhang, J. (2014) Abrasive Resistant Coatings-A Review. Lubricants, 2, 66-89. http://dx.doi.org/10.3390/lubricants2020066

[13] Friedrich, K. and Schlarb, A.K. (2013) Tribology of Polymeric Nanocomposites: Friction and Wear of Bulk Materials and Coatings. Butterworth-Heinemann, Oxford.

[14] Holmberg, K., Matthews, A. and Ronkainen, H. (1998) Coatings Tribology—Contact Mechanisms and Surface Design. Tribology International, 31, 107-120. http://dx.doi.org/10.1016/S0301-679X(98)00013-9

[15] Sidorenko, A., Ahn, H.-S., Kim, D.-I., Yang, H. and Tsukruk, V.V. (2002) Wear Stability of Polymer Nanocomposite Coatings with Trilayer Architecture. Wear, 252, 946-955. http://dx.doi.org/10.1016/S0043-1648(02)00048-0

[16] Gotlib-Vainshtein, K., Girshevitz, O., Sukenik, C.N., Barlam, D. and Cohen, S.R. (2014) A Nanometric Cushion for Enhancing Scratch and Wear Resistance of Hard Films. Beilstein Journal of Nanotechnology, 5, 1005-1015. http://dx.doi.org/10.3762/bjnano.5.114

[17] Browning, R., Lim, G.T., Moyse, A., Sun, L. and Sue, H.-J. (2006) Effects of Slip Agent and Talc Surface-Treatment on the Scratch Behavior of Thermoplastic Olefins. Polymer Engineering \& Science, 46, 601-608. http://dx.doi.org/10.1002/pen.20507

[18] Lörinczová, I. and Decker, C. (2014) Scratch Resistance of UV-Cured Acrylic Clearcoats. Surface Coatings International Part B: Coatings Transactions, 89, 133-143. http://dx.doi.org/10.1007/BF02699643

[19] Jiang, H., Browning, R.L., Hossain, M.M., Sue, H.-J. and Fujiwara, M. (2010) Quantitative Evaluation of Scratch Visibility Resistance of Polymers. Applied Surface Science, 256, 6324-6329. http://dx.doi.org/10.1016/j.apsusc.2010.04.011

[20] Hossain, M., Browning, M., Minkwitz, R. and Sue, H.-J. (2012) Effect of Asymmetric Constitutive Behavior on ScratchInduced Deformation of Polymers. Tribology Letters, 47, 113-122. http://dx.doi.org/10.1007/s11249-012-9967-y 